\title{
Construction project stakeholders' perceptions and expectations of their roles in BIM-based collaboration
}

\author{
Arvydas Kiaulakis $^{1}$, Tatjana Vilutiené ${ }^{2}$, Vaidotas Šarka ${ }^{3}$, Edita Šarkiené $\dot{4}^{4}$

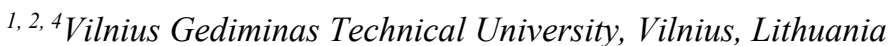 \\ ${ }^{3}$ Public institution "Skaitmenine statyba" ("Digital construction"), Vilnius, Lithuania \\ E-mail: 'arvydas.kiaulakis@vgtu.lt (correspondingauthor)
}

\begin{abstract}
The article presents the results of the survey aimed to analyze the attitude and perceptions regarding the use of BIM for data handling and analysis. Two target groups were researched, according to the role they play in building processes, namely public administrations (including tenants, owners, and building administrators) and Professionals (engineers / architects). The study conducted during the Net-UBIEP (Network for Using BIM to Increase the Energy Performance) project. The purpose of this study was to assess the implementation of building information modeling (BIM) as a tool and a process among key stakeholders in order to understand the current use of BIM, benefits of using BIM, obstacles of using BIM as well as possible future use. This study can be used as a pre-analysis of feedback from building users and construction professionals and can contribute to the co-adaptation process between BIM knowledge providers and BIM users.
\end{abstract}

Keywords: building information modelling, construction projects, collaboration.

\section{Introduction}

Building information modeling (BIM) refers to a set of technologies and organizational solutions that are expected to increase inter-disciplinary collaboration in the construction industry and to improve the productivity and quality of the design, construction, and maintenance of buildings (Miettinen \& Paavola, 2014). Although some criticism regarding the promises of building information modeling exists, BIM tools continue to proliferate within the construction industry and becoming more sophisticated. Therefore, the construction industry needs professionals who are not only skilled in their domain but are also good team members, communicators and lifelong learners (Dym, Agogino, Eris, Frey, \& Leifer, 2006). The identification of the competencies that need to be taught to ensure the collaborative workflows and integrated project deliverables is becoming increasingly important (Succar \& Sher, 2014).

Technology alone does not ensure that collaboration, communication and conflict management are efficient. Soft skills are essential in construction, as in many other industries. Negotiation, teamwork, and leadership are needed in the BIM project team. Davies, McMeel, and Wilkinson (2015) have revealed that a better definition of the expectations and activities of professionals and teams in a BIM project can help better understand the importance of soft skills in BIM-based collaboration. They form an important part of BIM roles applicable to projects implemented in the BIM environment.

The methodology of the research includes "focus groups" to provide insights into how experts think and provide a deeper understanding of the BIM competencies and BIM-related learning outcomes. Based on the results obtained in the "focus groups" the initial material for further analysis was gathered. Latter was used to prepare the questionnaires for the survey of targeted groups: professionals (engineers/architects) and public administrations (including tenants, owners and building administrators). The paper presents the summarized results of this survey. Although the survey is a valuable research tool, it normally asks closed-ended questions that limit the feedback that can be gained from a respondent. Therefore, the interviews with some representatives of targeted groups were conducted to gain more indepth information to supplement surveys.

At the first stage in a number of discussions, the experts selected the specific sets of social, personal and managerial skills as well as professional competencies and learning outcomes related to BIM application in construction projects. Those sets were included in the survey and distributed to the representatives of target groups. The article presents the results received from the survey of public administrations (including tenants, owners, and building administrators) and professionals (engineers/architects) of the construction industry.

(C) 2019 Authors. Published by VGTU Press. This is an open-access article distributed under the terms of the Creative Commons Attribution (http://creativecommons.org/licenses/by/4.0/) License, which permits unrestricted use, distribution, and reproduction in any medium, provided the original author and source are credited. 


\section{Literature review}

Recent efforts to identify BIM roles and competencies within the construction industry have focused on the definition and classifications of competencies (Ley \& Albert, 2003; Davies, Wilkinson, \& McMeel, 2017), identification and structuring of competencies for individual BIM profiles (Barison \& Santos, 2011; Succar, Sher, \& Williams, 2013; Succar \& Sher, 2014; Rahman, Alsafouri, Tang, \& Ayer, 2016).

The emergence of building information modeling has generated several BIM jobs. The analysis made by Uhm, Lee, and Jeon (2017) revealed that the top ten most frequently required BIM positions are BIM manager, BIM engineer, BIM coordinator, BIM technician, architect, mechanical, electrical, and plumbing (MEP) BIM engineer, BIM project manager, BIM designer, BIM MEP designer, and senior architect. However, despite great interest, questions regarding BIM jobs and their competencies still have no clear solution. Kassem, Raoff, and Ouahranib (2018) found that the literature does not clearly define the competencies and potential areas of expertise of each BIM specialist. Davies et al. (2017) note that many of client-driven BIM guide only specify roles and responsibilities in the project team, and neglect to address how the client organization will be managed in the BIM context during project life cycle and management of the building. Study of Barison and Santos (2011) revealed that BIM manager is most demanded profile, besides this profile has to possess a wide range of interdisciplinary knowledge, e.g. needs to be familiar with Information Technology, design and construction processes, management, BIM standards, BIM workflow, coordination practices, project management, construction drawings and costs, schedules and financial risks, parametric object-based design and other disciplines. The analysis of roles of BIM teams made by Gathercole and Thurairajah (2014) revealed that BIM Coordinators are expected to take over the broad range of duties, even though those are normally prescribed to the BIM Technicians.

Analyzed studies indicate that the required tools and skills for successful BIM adoption already exist in the industry. The review of Davies et al. (2017) highlights that a considerable part of the problem of unifying BIM implementation lies in semantics, rather than technology gaps. Therefore, the adoption of BIM and increased drive for collaboration brings a change to focus on aligning theory and practice.

The study of Olawumi and Chan (2019) reported the critical drivers that can enhance the successful implementation of both BIM and sustainability practices in construction projects. The three most significant include "increased number of subcontractors experienced with BIM projects", "greater awareness and experience level within the firm", and "increased involvement of project stakeholders in green projects". Other important categories were also identified, which include "organization and project-related issues", "industry culture", "legal issues", and "education, knowledge, and learning".

Based on analyses $\mathrm{Li}$, Zheng, $\mathrm{Si}$, and $\mathrm{Xu}$ (2019) proposed five strategies to mitigate challenges in BIM adoption in SMEs. These strategies, including cultivating the BIM perception of SMEs, integrated project delivery (IPD), strengthening the legal environment for BIM adoption in SMEs, and developing native software and standards and cloud-based technology, are mainly based on the view of governments, software developers, owners, and contractors who are the main stakeholders in the adoption of BIM by SMEs.

Ashworth, Tucker, and Druhmann (2018) analyzed the documentary side of BIM adoption in SMEs. They pointed out that clients are often unclear where to start and report feeling overwhelmed by the amount of information they need to read to get to grips with the fundamentals and clearly understand their role in BIM project. A key finding from this research is that practitioners are looking for good reference examples and guidance. It is critical that facility managers and clients acquire the skills to fully engage in the BIM process and clearly state their information needs so, that the supply chain can act on.

Having in mind the abovementioned, the purpose of this study was to assess the implementation of building information modeling (BIM) as a tool and a process among key stakeholders in order to understand the current use of BIM, benefits of using BIM, obstacles of using BIM as well as possible future use.

\section{Survey of construction project stakeholders}

The attitude and perceptions regarding the use of BIM for data handling and analysis of four target groups were researched, according to the role they play in building processes, namely public administrations, professionals (engineers/architects), technicians (installers/maintainers), tenants/owners/building administrator. This paper presents the results of two group's study (professionals and public administrations (including tenants, owners, and building administrators). 84 organizations participated in this survey.

At the first stage in a number of discussions, the experts selected the specific sets of social, personal and managerial skills as well as professional competencies related to BIM. Those sets were included in the survey and distributed to the representatives of target groups in every community participated in the project.

The $67 \%$ of the public administrations, tenants/owners/building administrators group responses received from the representatives of municipalities, while remaining $33 \%$ of the responses received from other public bodies like companies acting as building administrators or facility managers. Most of the respondents from public administrations, tenants/owners/building administrators group ( $42 \%$ ) hold the position of engineers, $21 \%$ hold managerial positions, 
least respondents indicated working as lawyers, project managers, architects, and superintendent. Most of the respondents from Professionals group (26\%) hold the position of project part/project manager, $22 \%$ hold designer positions, least respondents indicated working as construction the project manager, BIM specialist, BIM manager, technical supervisor.

The majority from the group of the public administrations, tenants/owners/building administrators are working in their area of expertise for more than 10-20 years (see Figure 1). Most common implemented projects valued up to 50000 thousand Euros (see Figure 2) and include residential (25\%) and infrastructure (32\%) projects. Majority from the group of the professionals working in their area for more than 5-10 years.

Interviewed group of the public administrations, tenants/owners/building administrators use or manage mainly publicly owned buildings, professionals use or manage mainly both - public and private (see Figure 3 ). According to their responses the current data about buildings (or parts of buildings) moderately accurate (38\%) or very inaccurate $(28 \%)$ (see Figure 4).

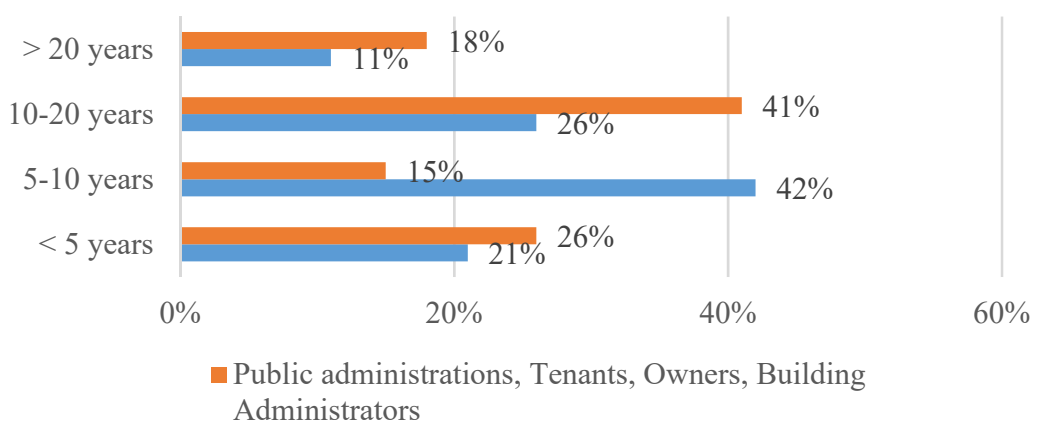

Figure 1. The distribution of responses to the question "How many years have you been working as a professional in company/organization?"

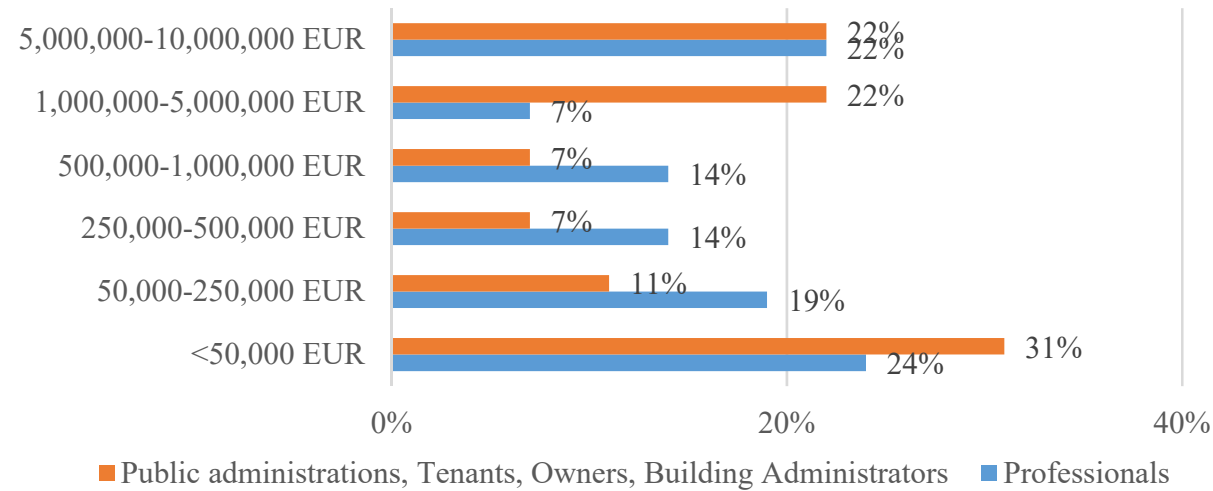

Figure 2. The distribution of responses to the question "What is the typical project value range company/organization is involved in?"

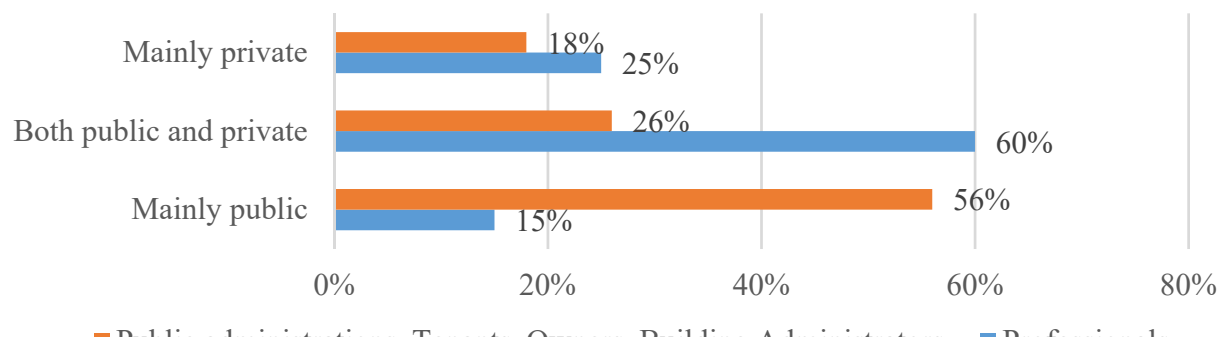

- Public administrations, Tenants, Owners, Building Administrators a Professionals

Figure 3. The distribution of responses to the question "What type of ownership of buildings company/organization uses?" 


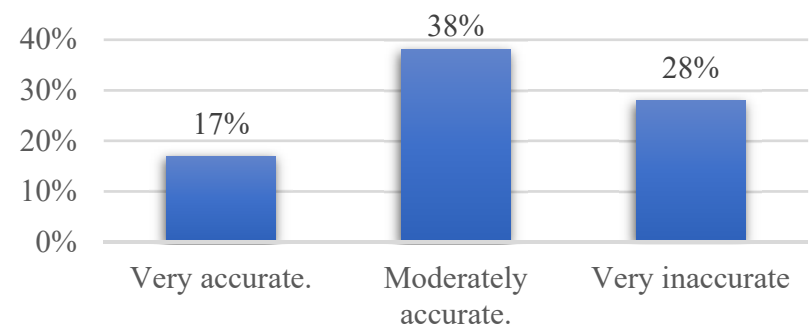

Figure 4. The distribution of responses to the question "How accurate is current data about buildings (parts of buildings) organization owns/manages/uses?” (responses of Public Administrations, Tenants/Owners/Building Administrators)

More than half of interviewed companies and organizations (54\% of public administrations and $73 \%$ of professionals) do not have an individual within either the operation or management groups who are responsible for maintenance and update of archived data on building and its' components (see Figure 5).

Only $11 \%$ of interviewed public administrations use BIM tools and methodology for data handling and analysis. Although most of the respondents (44\%) currently do not use the BIM tools for data handling, some expressed willingness to use (6\%) and remaining think that it is a good idea to use in future (39\%) (see Figure 6). The same number of respondents answered that there is a very high probability that their organization will use BIM in future (48\%) and that will not use BIM at all (4\%) (see Figure 7). Majority of organizations use BIM tools only to analyze models but do not create their own models (see Figure 8).

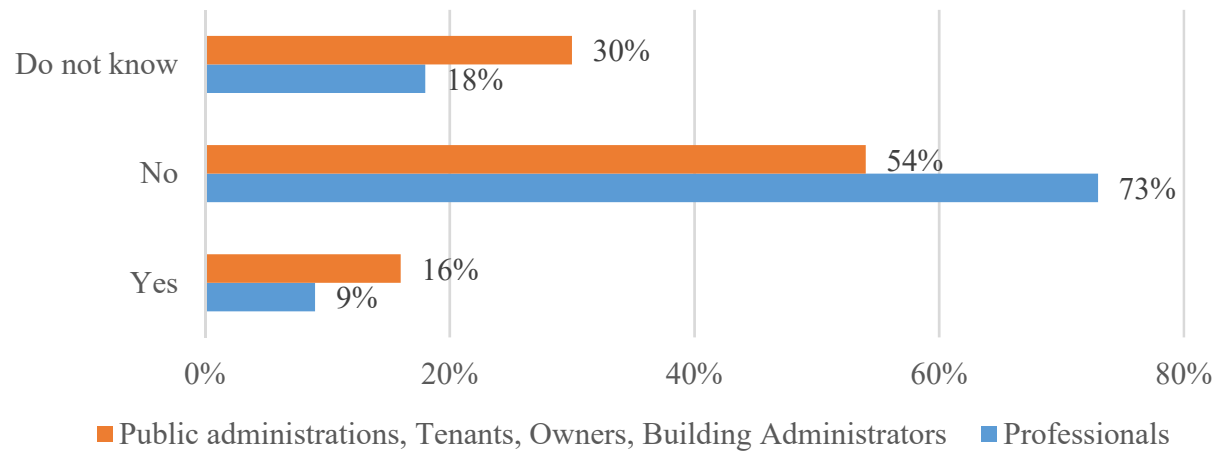

Figure 5. The distribution of responses to the question "Does company/organization have an individual within either the operation or management groups dedicated to update and maintain archived data?"

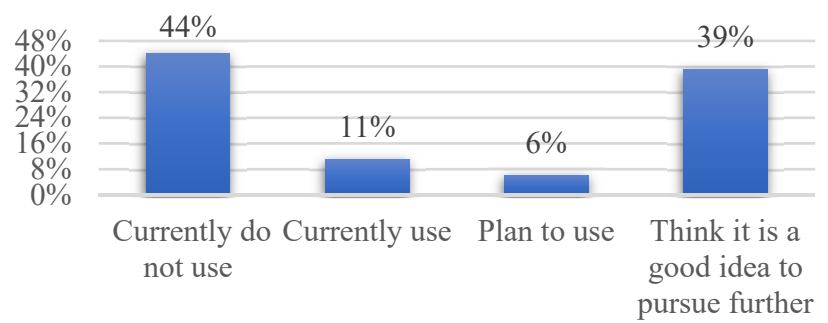

Figure 6. The distribution of responses to the question "Do company/organization currently use BIM for data handling?" (responses of Public Administrations, Tenants/Owners/Building Administrators)

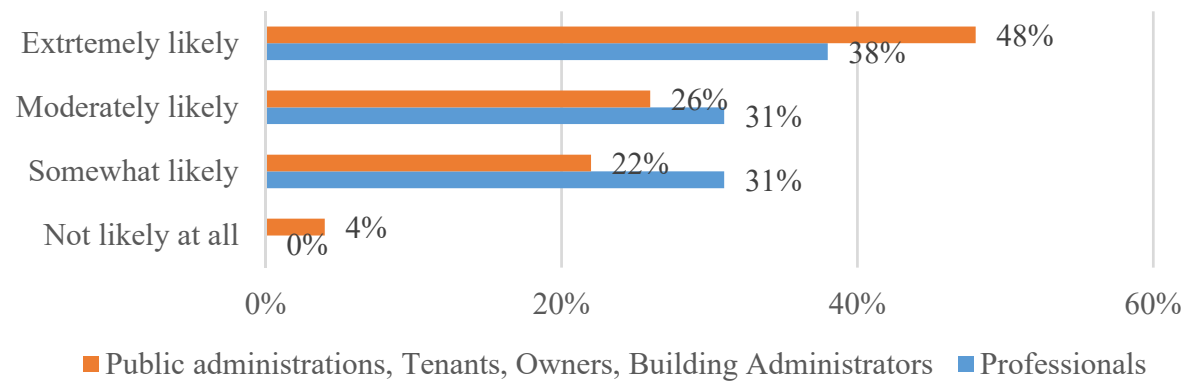

Figure 7. The distribution of responses to the question "If company/organization does not currently use BIM, how likely their company/organization will use BIM in future?" 
Create and analyse building information models

Use BIM tools to analyse models but do not create our own models

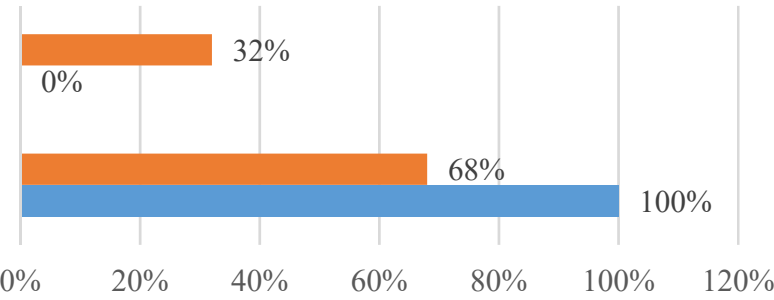

- Public administrations, Tenants, Owners, Building Administrators

- Professionals

Figure 8. The distribution of responses to the question “At which level does you company/organization utilize BIM?"

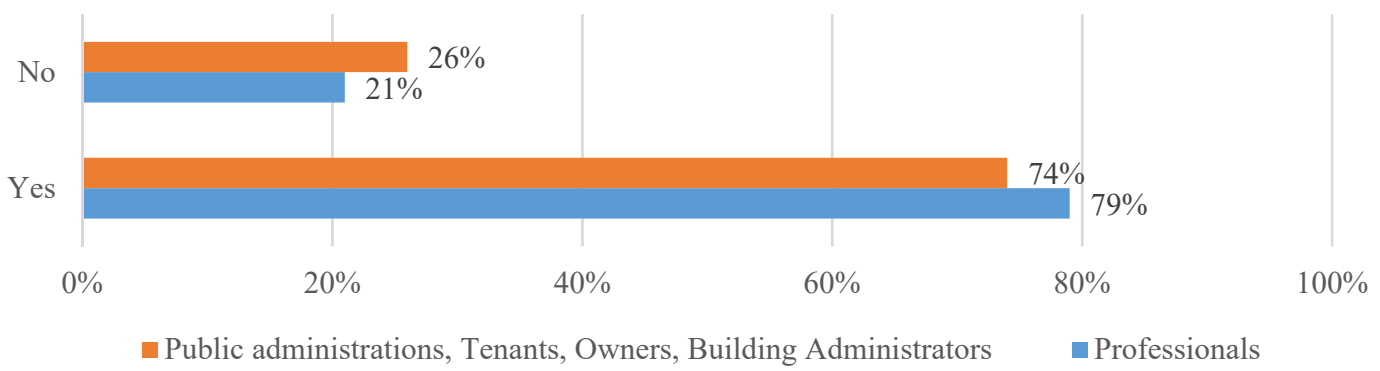

Figure 9. The distribution of responses to the question "If company/organization have not had experience with BIM, are you aware of the BIM approach?"

Although most of the respondents (74\%) declared that they are aware of the BIM approach (see Figure 9), 81\% of them have not heard about Construction Operations Building information exchange (COBie) (see Figure 10). Half of the respondents think that implementation costs associated with BIM (e.g. hardware, software, and staff training) outweigh benefits from BIM (see Figure 11). Despite the above fact, most of them believe that the implementation of BIM results in specific benefits. For example, $80 \%$ believe that the implementation of BIM results in productivity gains (see Figure 12). All respondents believe that widespread adoption of BIM will facilitate a reduction of costs and the number of errors (see Figure 13). Most of the respondents $(80 \%)$ believe that with the successful adoption of BIM, a new collaborative way of working and sharing of information is expected (see Figure 14).

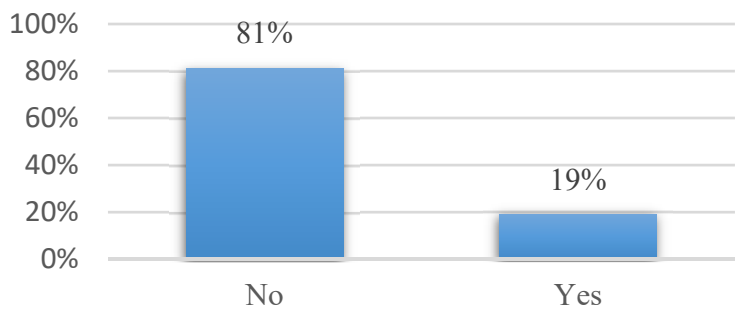

Figure 10. The distribution of responses to the question "Have company/organization heard about COBie (Construction Operations Building information exchange)?" (responses of Public Administrations, Tenants/Owners/Building Administrators)

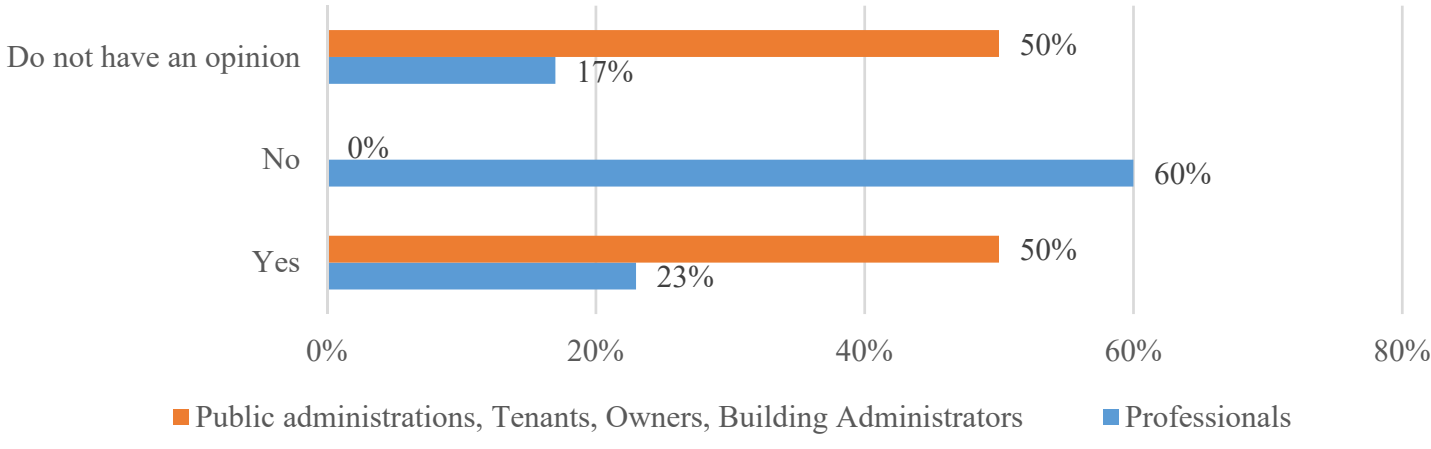

Figure 11. The distribution of responses to the question "Do company/organization believe that implementation costs associated with BIM (e.g. hardware, software and staff training) outweigh benefits from BIM?" 
Kiaulakis, A.; Vilutiene, T.; Šarka, V.; Šarkiene, E. 2019. Construction project stakeholders' perceptions and expectations of their roles in BIM-based collaboration

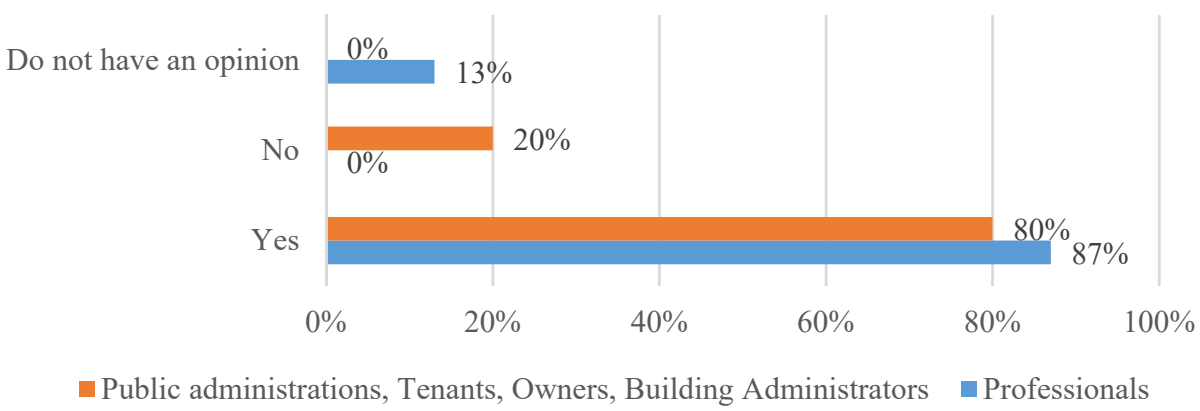

Figure 12. The distribution of responses to the question "Do company/organization believe that implementation of BIM results in productivity gains?"

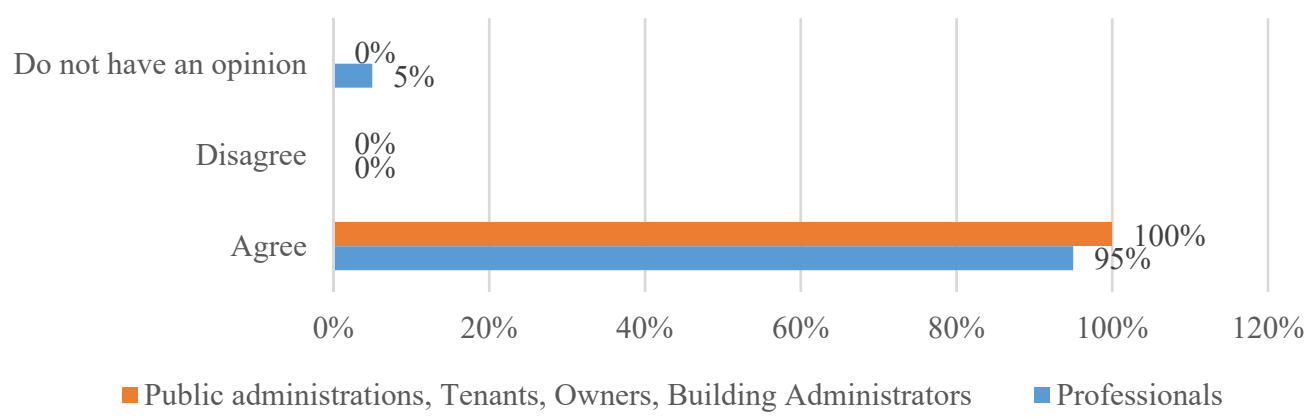

Figure 13. The distribution of responses to the question "The general opinion is that widespread adoption of BIM will facilitate a reduction of costs and number of errors. Do company/organization agree or disagree with this statement?"

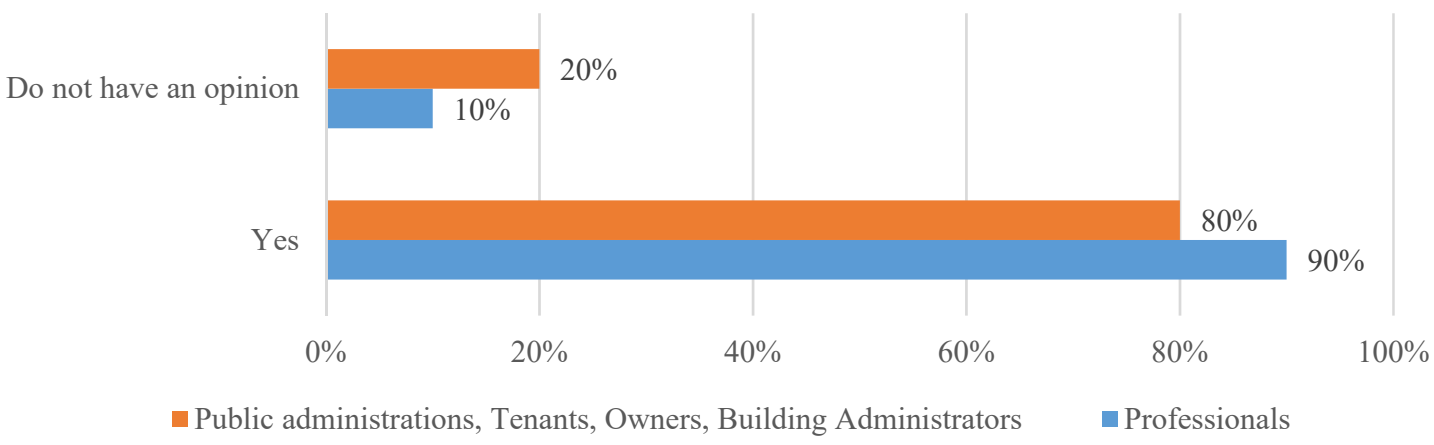

Figure 14. The distribution of responses to the question "With the successful adoption of BIM, a new collaborative way of working and sharing of information is expected. From company/organization experience, or in Your opinion, will this be achieved?"

Respondents also marked the barriers to BIM implementation. As the main barriers mentioned:

- Knowledge gaps in the fundamental understanding of BIM advantages.

- Cost of implementation (including software upgrades, training of employees).

- Clients do not demand the use of BIM due to the not perceived value of BIM by clients, and because it is not required in the construction process.

Respondents noted that practical training needed in order to reduce the knowledge gaps. Moreover, more than $80 \%$ of respondents marked that the certification of BIM competencies will benefit the representatives of the construction sector. Respondents also noticed that orders of Ministries that makes obligatory use of BIM in energy efficiency related projects will encourage its' faster adoption in organizations. In spite of this, the majority of respondents foresee that companies and organizations will be left behind and struggle to survive if they do not adopt BIM quickly enough. 


\section{Conclusions}

The results of the survey revealed that despite the high implementation costs associated with BIM, most of the clients and professionals believe that the implementation of BIM results in specific benefits, e.g. productivity gains. All respondents believe that widespread adoption of BIM will facilitate a reduction of costs and errors. Most of the respondents believe that with the successful adoption of BIM, a new collaborative way of working and sharing of information is expected.

The results reveal that research on BIM knowledge and skills is recently growing area, so confirming the importance of applications of BIM for data handling. The interest in recent research on BIM knowledge and skills show great potential for implementing common frameworks for the development of BIM competencies.

The BIM applications for information management have a promising future and have to be promoted within buildings related sectors. There are many opportunities for using BIM in integration with available technologies for information management like classification tools, cloud computing, laser scanning, visualization techniques, simulation software, etc.

Whereas the number of developments in BIM area is constantly growing, the future work should be done to extend the analysis of BIM applications and necessary extra skills and knowledge to be added in related BIM profiles. In spite of these facts, this study can be used as a pre-analysis of feedback from building users and construction professionals and can contribute to the co-adaptation process between BIM knowledge providers and BIM users.

\section{Acknowledgements}

This research was co-funded by Horizon 2020 programme of the European Union, project "Network for Using BIM to Increase the Energy Performance (Net-UBIEP)" [grant number 754016].

\section{References}

Ashworth, S., Tucker, M., \& Druhmann, C. (2019). Critical success factors for facility management employer's information requirements (EIR) for BIM. Facilities, 37(1/2), 103-118. https://doi.org/10.1108/F-02-2018-0027

Barison, M. B., \& Santos, E. T. (2011). The competencies of BIM specialists: A comparative analysis of the literature review and job ad descriptions. Computing in Civil Engineering (pp. 594-602). https://doi.org/10.1061/41182(416)73

Davies, K., McMeel, D., \& Wilkinson, S. (2015, October). Soft skills requirements in a BIM project team. In J. Beetz, T. Hartmann, L. van Berlo, R. Amor (Eds.), Proceedings of the $32^{\text {nd }}$ International Conference of CIB W78 (pp. 108-117).

Davies, K., Wilkinson, S., \& McMeel, D. (2017). A review of specialist role definitions in BIM guides and standards. Journal of Information Technology in Construction (ITcon), 22(10), 185-203.

Dym, C. L., Agogino, A. M., Eris, O., Frey, D. D., \& Leifer, L. J. (2006). Engineering design thinking, teaching, and learning. IEEE Engineering Management Review, 34(1), 65-92. https://doi.org/10.1109/EMR.2006.1679078

Gathercole, M., \& Thurairajah, N. (2014). The influence of BIM on the responsibilities and skills of a project delivery team. In International Conference on Construction in a Changing World. Heritance Kandalama, Sri Lanka.

Kassem, M., Raoff, N. L. A., \& Ouahranib, D. (2018). Identifying and analyzing BIM specialist roles using a competency-based approach. In Proceedings of the Creative Construction Conference (pp. 1044-1051). Ljubljana. https://doi.org/10.3311/CCC2018-135

Ley, T., \& Albert, D. (2003). Identifying employee competencies in dynamic work domains: methodological considerations and a case study. Journal of Universal Comuter Science, 9(12), 1500-1518.

Li, P., Zheng, S., Si, H., \& Xu, K. (2019). Critical challenges for BIM adoption in small and medium-sized enterprises: Evidence from China. Advances in Civil Engineering, 2019, ID 9482350. https://doi.org/10.1155/2019/9482350

Miettinen, R., \& Paavola, S. (2014). Beyond the BIM utopia: Approaches to the development and implementation of building information modeling. Automation in Construction, 43, 84-91. https://doi.org/10.1016/j.autcon.2014.03.009

Olawumi, T. O., \& Chan, D. W. M. (2019). Critical success factors for implementing building information modeling and sustainability practices in construction projects: A Delphi survey. Sustainable Development, 27(4), 587-602. https://doi.org/10.1002/sd.1925

Rahman, R. A., Alsafouri, S., Tang, P., \& Ayer, S. K. (2016). Comparing building information modeling skills of project managers and BIM managers based on social media analysis. Procedia Engineering, 145, 812-819. https://doi.org/10.1016/j.proeng.2016.04.106

Succar, B., \& Sher, W. (2014). A Competency knowledge-base for BIM learning. Australasian Journal of Construction Economics and Building-Conference Series, 2(2), 1-10. https://doi.org/10.5130/ajceb-cs.v2i2.3883

Succar, B., Sher, W., \& Williams, A. (2013). An integrated approach to BIM competency assessment, acquisition and application. Automation in Construction, 35, 174-189. https://doi.org/10.1016/j.autcon.2013.05.016

Uhm, M., Lee, G., \& Jeon, B. (2017). An analysis of BIM jobs and competencies based on the use of terms in the industry. Automation in Construction, 81, 67-98. https://doi.org/10.1016/j.autcon.2017.06.002 